\title{
Study of the Role of Body Mass Index and Serum Leptin as Potential Risk Factors in Patients with Lifelong Premature Ejaculation
}

\author{
Original \\ Article \\ Tarek Tawfik', Mohamed Aref ${ }^{2}$, Sameh Gamal El Din ${ }^{3}$, Mohamed Abd El Mawgood $^{4}$, \\ Ahmed Khattab $^{5}$ \\ ${ }^{1,4}$ Department of Dermatology \& STDs Al-Azhar University, ${ }^{2}$ Chemical Pathology Al-Azhar \\ University, ${ }^{3}$ Department of Andrology \& STDs Cairo University, ${ }^{5}$ Faculty of Medicine Al- \\ Azhar University
}

\begin{abstract}
Introduction: several studies demonstrated the potential role of serum leptin in patients with premature ejaculation. Aim: we aimed in this study to evaluate the correlation between body mass index, serum leptin and intra-vaginal ejaculation latency time in patients with lifelong premature ejaculation and healthy controls.

Patients and Methods: this study was carried out on 80 consecutive patients and controls. Body mass index was measured in the patients and the controls. Serum leptin was measured in both groups at the end of the study. Additionally, the patients and the controls were asked to measure intra vaginal ejaculation latency time (IELT) by stop watch handled by their wives for 2 successive months.

Results: our prospective analysis revealed a highly significant association between body mass index and serum leptin and intra-vaginal ejaculation latency time among the cases ( $p$-value $<0.001,<0.001$ respectively). Additionally, body mass index (BMI) did reveal significant association with intra-vaginal ejaculation latency time $(p$-value $=0.014)$ only, without any association with serum leptin $(p$-value $=0.391)$ among the controls.

Discussion: the current study demonstrated a statistically significant association between BMI and serum leptin and IELT in the patients with lifelong premature ejaculation. Additionally, the results revealed a statistically significant association between BMI and IELT in the controls without any association with the serum leptin.

Conclusion: the current study highlights the role of both body mass index and serum leptin as potential risk factors in patients with lifelong premature ejaculation. Eventually, future studies are required to duplicate this interesting association between body mass index, serum leptin and intra-vaginal ejaculation latency time in patients with lifelong premature ejaculation.
\end{abstract}

Key Words: Body mass index (BMI), intravaginal ejaculation latency time (IELT), lifelong premature ejaculation (LPE), serum leptin.

Revised: 27 August 2017, Accepted: 10 September 2017

Corresponding Author: Sameh F. Gamal El Din, Tel.: 01227109309, E-mail: samehfayek@hotmail.com

ISSN: 2090-6048, September 2017, Vol. 7, No. 3

\section{INTRODUCTION}

Lifelong premature ejaculation (LPE) is operationally defined as the inability to delay ejaculation for more than 1 minute after vaginal penetration occurring on more than $90 \%$ of occasions of sexual intercourse with any sexual partner that is by accompanied feelings of frustration of both the patient and his partner with avoidance of sexual intimacy.1 Recently, Althof et al (2014) proposed updated guidelines for diagnosis and treatment of this ejaculatory dysfunction. 2 Two studies, involving five nations, revealed that $2.5 \%$ of men had an intra-vaginal ejaculation latency time (IELT) of less than 1 minute and $6 \%$ of less than 2 minutes $\mathrm{PE}^{[3-4]}$. This made the prevalence of LPE unlikely to exceed $4 \%$ of the general population ${ }^{[5-7]}$. Leptin is a mainly adipocyte-secreted protein that was discovered by Freidman's group who reported the cloning of the obese (ob) gene, responsible for the typical phenotype of obesity, diabetes and insulin resistance in ob/ob mice. 8 Additionally, leptin was proposed to have an emerging function as a metabolic and neuroendocrine hormone, besides its obvious role in body weight regulation ${ }^{[9]}$. Body mass index (BMI) and fat mass associate strongly with plasma Leptin level in humans as the latter is synthesized mainly by fat cells $s^{[10-13]}$.

About two decades before, the role of serum leptin in the pathogenesis of premature ejaculation was heightened. The role of serum leptin in premature ejaculation was extensively studied using animal models. Hastings and his 
colleagues (2002) and Fernandez-Galaz and his colleagues (2010) postulated that leptin may decrease the content of central 5-hydroxytryptamine (5-HT) which might be due to increased metabolism or inhibition of the activity of 5-HT, thereby it plays an important role in the pathogenesis of premature ejaculation ${ }^{[14-15]}$.

Eventually, Atmaca and his colleagues (2002) and Nikoobakht and his colleagues (2008) reported that serum leptin levels in the patients with PE were significantly higher than that in healthy controls ${ }^{[16-17]}$. Till now, there is no more information about the risk factors in lifelong premature ejaculation other than genetic hypothesis that was firstly postulated by Waldinger et al $(1998)^{[18]}$. On the other hand, Gao et al (2013) and Zhang et al (2013) stated that several comorbidities are more prevalent among Chinese patients with acquired premature ejaculation (APE) and premature like ejaculatory dysfunction (PLED) such as age, smoking, anxiety, lower frequency of intercourse and higher BMI ${ }^{[19}$ ${ }^{-20]}$. We aimed in the present study to evaluate the correlation between BMI, serum leptin and IELT in patients with LPE and the potential role of both BMI and serum leptin as risk factors in patients with LPE.

\section{PATIENTS AND METHODS}

\section{Sample recruitment}

This study was conducted during the period from October 2014 to June 2015 in Andrology Unit of the Dermatology \& STDs department and Clinical Pathology Department, Al-Azhar University, Cairo, Egypt. Eighty consecutive patients and controls aged 20- 40 years were recruited to join this study.

\section{Inclusion criteria of the patients}

They should be married for at least one year with stable and continuous marital relationship. They presented with LPE (intra-vaginal ejaculation latency time $<1$ minute) and inability to satisfy their partners.

\section{Exclusion criteria of the patients}

Patients with erectile dysfunction (men had score $<21$ using validated Arabic version of international index of erectile function (IIEF)), reduced sexual desire or inhibited male orgasm were excluded from the study, in addition to presence of urinary tract infection, mental disorders, physical illnesses, alcohol or drug abuse and any psychotropic medications affecting ejaculatory function.

\section{Inclusion criteria of the controls}

They were potent individuals who attended our clinic seeking fertility with their IELTs at least more than 3 minutes that was self-estimated by the controls themselves using stopwatch ${ }^{[7]}$.

General and local examinations and withdrawal of the blood sample from the patients and controls.

Approval of the local ethical committee that conforms to Helsinki declaration (2004) was obtained after getting in writing signed consents from the patients and controls including the purpose of the study and to measure weight, height, span and BMI and the need to withdraw $(5 \mathrm{ml})$ of venous blood from each patient and control for measuring serum leptin at the end of the study. Genital examination was done for all the participants and did not reveal any abnormality.

\section{Evaluation of the patients}

We used validated Arabic version of IIEF to determine the erectile function of patients included in this study. 21 Urinary tract infections of the patients were excluded by microscopic examination of two glasses of urine. Both the patients and controls were asked to measure IELT for 2 successive months using stop watch handled by their wives. The wives were asked to measure the first coitus only. Finally, the wives were instructed to measure the time taken between intromission and the sensation of ejaculation inside the vagina.

\section{Steps of measuring serum leptin}

Peripheral venous blood was taken, at 8 am after 12 hours of fasting. The blood samples were placed in tubes containing ethylenediaminetetraacetic acid, centrifuged for 20 minutes at 2,000 rpm and the serum was separated. The samples were stored at $-70^{\circ} \mathrm{C}$ liquid nitrogen until analysis. Leptin was measured using leptin Enzyme Immunoassay Kit from California U.S.A.; a solid phase enzyme linkedimmunosorbent assay (ELISA) based on the sandwich principle $^{[13]}$. The sensitivity of the test was $0.5 \mathrm{ng} / \mathrm{mL}$. The micro-titre wells were coated with a monoclonal antibody directed towards a unique antigenic site on a leptin molecule. An aliquot of patient sample containing endogenous leptin was incubated in the coated well with a specific rabbit anti leptin antibody. A sandwich complex was formed. After incubation the unbound material was washed off and an anti-rabbit peroxidase conjugate was added for detection of the bound leptin. After the substrate solution being added, the intensity of the colour developed was proportional to the concentration of leptin in the patient sample. 


\section{Statistical analysis}

Data were coded and entered using the statistical package SPSS (Statistical Package for the Social Sciences) version $^{[23]}$. Data was summarized using mean, standard deviation, median, minimum and maximum in quantitative data and using frequency (count) and relative frequency (percentage) for categorical data. Comparisons between quantitative variables were done using the non-parametric Mann-Whitney test.22 For comparing categorical data, Chi square ${ }^{[2]}$ test was performed. Exact test was used instead when the expected frequency was less than 5.23 Correlations between quantitative variables were done using Spearman correlation coefficient ${ }^{[24]}$.

ROC curve was constructed with area under curve analysis performed to detect best cutoff value of body mass index for detection of cases. Binary logistic regression model fitting was also used to obtain crude and adjusted odds ratios (OR).25 $P$-values less than 0.05 were considered as statistically significant.

\section{RESULTS}

Socio-demographic characteristics of cases and controls

The current study revealed that the mean age of the controls was higher than that the cases. However, this difference was statistically insignificant ( $p$-value $=0.91$ ). The mean of the BMI was statistically higher in the controls than that the cases ( $p$-value $=0.01)$. In addition, the mean of the serum leptin was statistically higher in the cases than that the controls $(p$-value $=<0.001)$. (See table 1)
Association between BMI and IELT in cases and controls

The current study demonstrated highly significant association between BMI, serum leptin and IELT among the cases $(p$-value $=<0.001,<0.001$, respectively). Meanwhile, body mass index revealed significant association with IELT ( $\mathrm{p}$-value $=0.014$ ) only, without any association with the serum leptin $(\mathrm{p}$-value $=0.391)$ among the controls (See table 2). Interestingly, the receiver operation characteristic curve (ROC) revealed significant association between BMI and IELT in the cases with $p$-value $=0.01$, area under curve (AUC) $=0.666$ and cutoff value $=28.5$. Additionally, upper and lower bounds of $95 \%$ confidence interval were 0.798 and 0.535 , respectively. Finally, Binary logistic regression with premature ejaculation as dependent factor as BMI as independent predictor adjusted for age and serum leptin demonstrated significant association with IELT $(p$-value $=0.001)($ See figure 1$)$.

\section{Association between serum leptin and IELT in the cases and the controls}

Fitting a binary logistic regression model on the data showed a significant association between serum leptin and IELT ( $p$-value $<0.001$ ) and $1 \mathrm{ng} / \mathrm{mL}$ increase in serum leptin level, increasing the odds of PE by a factor of 1.658 (95\% confidence interval [CI] 1.254-2.193). After adjusting for age and BMI, the high leptin level was still associated with PE and BMI (adjusted odds ratio $(\mathrm{OR})=2.616 ; 95 \%$ CI 1.551-4.413) with increase in the calculated OR ( $p$-values $<0.001,0.001$, respectively) (Figure 2). Meanwhile, serum leptin did not reveal any significant association with the controls $(p$-value $=0.54)$ (See table 3).

Table 1: Socio-demographic characteristics of patients and controls

\begin{tabular}{|c|c|c|c|c|c|c|c|c|c|}
\hline & \multicolumn{8}{|c|}{ group } & \multirow{3}{*}{$P$ value } \\
\hline & \multicolumn{4}{|c|}{ cases } & \multicolumn{4}{|c|}{ control } & \\
\hline & Mean & SD & Minimum & Maximum & Minimum & SD & Mean & Maximum & \\
\hline leptin & 6.47 & 8.39 & 1.20 & 31.00 & 1.59 & 1.68 & .40 & 5.40 & $<0.001$ \\
\hline Age ( years) & 32.35 & 10.4 & 25.00 & 40.00 & 32.6 & 5.05 & 24.00 & 40.00 & 0.91 \\
\hline IELT (min) & .71 & .18 & .50 & .98 & 10.92 & 3.28 & 3.00 & 15.00 & $<0.001$ \\
\hline BMI $\left(\mathrm{kg} / \mathrm{m}^{\wedge} 2\right)$ & 26.10 & 2.49 & 22.00 & 31.00 & 30.00 & 6.71 & 20.00 & 40.00 & 0.010 \\
\hline
\end{tabular}


Table 2: Correlation between BMI and other parameters among controls and patients respectively

\begin{tabular}{|c|c|c|c|}
\hline & & $\begin{array}{c}\text { BMI } \\
(\mathrm{kg} / \mathrm{m} 2) \\
\text { (controls) }\end{array}$ & $\begin{array}{c}\text { BMI } \\
(\mathrm{kg} / \mathrm{m} 2) \\
\text { (patients) }\end{array}$ \\
\hline \multirow{3}{*}{ IELT (min) } & Correlation Coefficient & $-.387-$ & $-.494-$ \\
\hline & $P$ value & .014 & $<0.001$ \\
\hline & $\mathrm{N}$ & 40 & 40 \\
\hline \multirow{3}{*}{ Serum leptin } & Correlation Coefficient & $-.139-$ & .885 \\
\hline & $P$ value & .391 & $<0.001$ \\
\hline & $\mathrm{N}$ & 40 & 40 \\
\hline
\end{tabular}

Table 3: Correlation between serum leptin and other parameters among controls and patients respectively

\begin{tabular}{|c|c|c|c|}
\hline & & $\begin{array}{c}\text { Serum } \\
\text { Leptin } \\
\text { (controls) }\end{array}$ & $\begin{array}{c}\text { Serum leptin } \\
\text { (patients) }\end{array}$ \\
\hline \multirow{3}{*}{ IELT (min) } & Correlation Coefficient & $-.099-$ & $-.539-$ \\
\hline & $P$ value & .542 & $<0.001$ \\
\hline & $\mathrm{N}$ & 40 & 40 \\
\hline \multirow{3}{*}{ BMI (kg/m2) } & Correlation Coefficient & $-.139-$ & .885 \\
\hline & $\mathrm{P}$ value & .391 & $<0.001$ \\
\hline & $\mathrm{N}$ & 40 & 40 \\
\hline
\end{tabular}

\section{DISCUSSION}

The current study demonstrated a statistically significant association between BMI and serum leptin and IELT in the patients with lifelong premature ejaculation. Additionally, the results revealed a statistically significant association between BMI and IELT in the controls without any association with the serum leptin. Also, BMI was higher in the controls than the cases which can be explained by the fact that the mean age of the controls was higher that of the cases. This finding can be seen in line with Reas et al (2007) who demonstrated that accelerated weight gain occurs mainly during younger adulthood as it represents a critical time period due to ensuant lifestyle changes involving energy expenditure, dietary intake and they inaccurately assume their weight falls into a normal weight range ${ }^{[26]}$. Finally, the current results affirmed the significant relation between BMI and IELT in the patients with lifelong premature ejaculation by the fact that serum leptin is statistically higher in the cases than the controls which was consistent with the findings of Nikoobakht et al (2008) and Gökçe et al (2010) who also stated an inverse relationship between IELT and $\mathrm{BMI}^{[17,27]}$.

To the best of our knowledge, this study was the first report to demonstrate a significant relation between BMI and serum leptin in the cases as Nikoobakht and his colleagues as they failed to reveal an association between BMI and serum leptin in their studied cases ${ }^{[17]}$. Recently, Ventus and his colleague (2016) assumed a potential association between BMI and $\mathrm{PE}^{[28]}$. In contrast, Salama and his colleagues (2017) revealed significant prevalence of PE among patients with metabolic syndrome. However, they 
failed to demonstrate a significant association between $\mathrm{BMI}$ and $\mathrm{PE}^{[29]}$. Eventually, some limitations of this study must be addressed. First, this study was of small sample size and the cases and the controls were not homogenous. Finally, we did not include patients with secondary premature ejaculation to extend the scope of this research.

\section{CONCLUSION}

The current study highlights the role of BMI and serum leptin as potential risk factors in the patients with LPE. Eventually, future studies are required to duplicate this interesting association between BMI and serum leptin and IELT in patients with LPE. Also, further studies are needed to evaluate the role of physical exercise on the IELT in patients with lifelong premature ejaculation.

\section{CONFLICT OF INTEREST}

There are no conflicts of interest.

\section{REFERENCES}

1. McMahon CG, Althof SE, Waldinger MD, et al. An evidence-based definition of lifelong premature ejaculation: report of the International Society for Sexual Medicine (ISSM) Ad Hoc Committee for the definition of premature ejaculation. J Sex Med. 2008; $5,1590-1606$.

2. Althof SE, McMahon CG, Waldinger MD et al. An update of the International Society of Sexual Medicine's guidelines for the diagnosis and treatment of premature ejaculation (PE). J Sex Med. 2014; 11(6), $1392-422$.

3. Waldinger M, Quinn P, Dilleen M, et al. A multinational population survey of intravaginal ejaculation latency time. J Sex Med. 2005; 2, 292-297.

4. Waldinger M, McIntosh J, Schweitzer DH. A five-nation survey to assess the distribution of the intravaginal ejaculatory latency time among the general male population. J Sex Med. 2009; 6, 2888-2895.

5. Althof $\mathrm{S}, \mathrm{Abdo} \mathrm{C}$, Dean J, et al. International Society for Sexual Medicine's Guidelines for the diagnosis and treatment of premature ejaculation. J Sex Med. 2010; 7, 2947-69.

6. Serefoglu EC, Yaman O, Cayan S, et al. Prevalence of the complaint of ejaculating prematurely and the four premature ejaculation syndromes: results from the
Turkish Society of Andrology Sexual Health Survey. J Sex Med. 2011; 8, 540-548.

7. Serefoglu EC, McMahon CG, Waldinger MD, et al. An evidence-based unified definition of lifelong and acquired premature ejaculation: Report of the second International Society for Sexual Medicine Ad Hoc Committee for the Definition of Premature Ejaculation. J Sex Med. 2014; 11(6), 1423- 41.

8. Zhang Y, Proenca R, Maffei M, et al. Positional cloning of the mouse obese gene and its human homologue. Nature. 1994; 372, 425- 431.

9. Wauters M, Considine RV, Van-Gaal LF. Human leptin: from an adipocyte hormone to an endocrine mediator. Eur J Endocrinol. 2000; 143(3), 293- 311.

10. LoÈnnqvist F, Arner $\mathrm{P}$, Nordfors $\mathrm{L}$, et al. Over expression of the obese (ob) gene in adipose tissue of human obese subjects. Nature Medicine. 1995; 1, 950- 953.

11. Hamilton BS, Paglia D, Kwan AY, et al. Increased obese mRNA expression in omental fat cells from massively obese humans. Nature Medicine. 1995; 1, 953- 956.

12. Maffei M, Halaas J, Ravussin E, Pratley RE, Lee GH et al. Leptin levels in human and rodent: measurement of plasma leptin and ob RNA in obese and weightreduced subjects. Nature Medicine 1995; 1: 1155- 1161.

13. Considine, RV, Sinha MK, Heiman ML, et al. Serum immunoreactive-leptin concentrations in normalweight and obese humans. New England Journal of Medicine. 1996; 334, 292 -295.

14. Hastings JA, Wiesner G, Lambert G, et al. Influence of leptin on neurotransmitter over flow from the rat brain in vitro. Regul Pept. 2002; 103(2 -3), 67 -74.

15. Fernandez-Galaz MC, Fernandez-Agullo T, Carrascosa $\mathrm{JM}$, et al. Leptin accumulation in hypothalamic and dorsal raphe neurons is inversely correlated with brain serotonin content. Brain Res. 2010; 1329, 194- 202.

16. Atmaca M, Kuloglu M, Tezcan E, et al. Serum leptin levels in patients with premature ejaculation. Arch Androl. 2002; 48(5), 345 -50.

17. Nikoobakht MR, Tajik P, Karami AA, et al. Premature ejaculation and serum leptin level: a diagnostic casecontrol study. J Sex Med. 2008; 5(12), 2942 -6. 
18. Waldinger M, Rietschel M, Nothen $\mathrm{N}$, et al. Familial occurrence of primary premature ejaculation. Psychiatr Genet. 1998; 8, 37-40.

19. Gao J, Zhang X, Su P, et al. Prevalence and factors associated with the complaint of premature ejaculation and the four premature ejaculation syndromes: a large observational study in China. J Sex Med. 2013; 10(7):1874 -81. doi: 10.1111/jsm.12180. Epub 2013 May 7.

20. Zhang X, Gao J, Liu J, et al. Distribution and factors associated with four premature ejaculation syndromes in outpatients complaining of ejaculating prematurely. J Sex Med. 2013; 1603-1611.

21. Shamloul R, Ghanem H, Abou-zeid A. Validity of the Arabic version of the sexual health inventory for men among Egyptians. International Journal of Impotence Research. 2004; 16, 452-455.

22. Chan YH. Biostatistics102: Quantitative Data Parametric \& Non-parametric Tests. Singapore Med J. 2003a; 44(8), $391-396$.

23. Chan YH. Biostatistics 103: Qualitative Data -Tests of Independence. Singapore Med J. 2003b; 44(10), 498- 503.
24. Chan YH. Biostatistics 104: Correlational Analysis. Singapore Med J. 2003c 44(12), 614 -619.

25. Chan YH. Biostatistics 202: logistic regression analysis. Singapore Med J. 2004; 45(4), 149 -153.

26. Reas DL, Nygård JF, Svensson E, et al. Changes in body mass index by age, gender, and socio-economic status among a cohort of Norwegian men and women (19902001-). BMC Public Health. 2007; 30,7:269

27. Gökçe A, Ekmekcioglu O. Insight on pathogenesis of lifelong premature ejaculation: inverse relationship between lifelong premature ejaculation and obesity. Int J Impot Res. 2010 Jul-Aug; 22(4):2514-. doi: 10.1038/ijir.2010.11. Epub 2010 Jun 24

28. Ventus D, Jern P. Lifestyle Factors and Premature Ejaculation: Are Physical Exercise, Alcohol Consumption, and Body Mass Index Associated With Premature Ejaculation and Comorbid Erectile Problems? J Sex Med. 2016; 13(10), 1482- 7. doi: 10.1016/j.jsxm.2016.08.007. Epub 2016 Aug 31.

29. Salama N, Eid A, Swedan A, et al. Increased prevalence of premature ejaculation in men with metabolic syndrome. Aging Male. 2017; 17-. doi: 10.108013685538.2016.1277515/. [Epub ahead of print]. 